\title{
Graphene oxide membranes with high permeability and selectivity for dehumidification of air
}

\author{
Yongsoon Shin, ${ }^{1}$ Wei Liu, ${ }^{2}$ Birgit Schwenzer, ${ }^{1}$ Sandeep Manandhar, ${ }^{3,4}$ Dylan Chase- \\ Woods, ${ }^{2,5}$ Mark H. Engelhard, ${ }^{3}$ Ram Devanathan, ${ }^{2}$ Leonard S. Fifield, ${ }^{2}$ Wendy D. Bennett, ${ }^{2}$ \\ Bojana Ginovska ${ }^{1}$ David W. Gotthold ${ }^{2 *}$ \\ ${ }^{1}$ Fundamental and Computational Sciences Directorate, Pacific Northwest National \\ Laboratory, Richland, WA 99352, USA \\ ${ }^{2}$ Energy and Environment Directorate, Pacific Northwest National Laboratory, Richland, WA \\ 99352, USA \\ ${ }^{3}$ W. R. Wiley Environmental Molecular Sciences Laboratory, Pacific Northwest National \\ Laboratory, Richland, WA 99352, USA \\ ${ }^{4}$ Department of Materials Science \& Engineering, University of Washington, Seattle, WA 98195 \\ ${ }^{5}$ Department of Physics, University of Washington, Seattle, WA 98195
}

\begin{abstract}
Hierarchically stacked 2D graphene oxide (GO) membranes are a fascinating and promising new class of materials with the potential for radically improved water vapor/gas separation with excellent selectivity and high permeability. This paper details dehumidification results from flowing gas mixtures through free-standing GO membrane samples prepared by a casting method. The first demonstrated use of free-standing GO membranes for water vapor separation reveals outstanding water vapor permeability and $\mathrm{H}_{2} \mathrm{O} / \mathrm{N}_{2}$ selectivity. Free-standing $\mathrm{GO}$ membranes exhibit extremely high water vapor permeability of 1.82 x $10^{5}$ Barrer and a water vapor permeance of $1.01 \times 10^{-5} \mathrm{~mol} / \mathrm{m}^{2} \mathrm{sPa}$, while the nitrogen permeability was below the system's detection limit, yielding a selectivity $>10^{4}$ in $80 \%$ relative humidity (RH) air at $30.8^{\circ} \mathrm{C}$. The results show great potential for a range of energy conversion and environmental applications.
\end{abstract}

\footnotetext{
* Corresponding author. Tel.: +1-509-375-2073; E-mail: david.gotthold@pnnl.gov (D. W. Gotthold).
} 


\section{Introduction}

Dehumidification is an energy intensive and widely needed process in building airconditioning [1], dehydration of natural gases [2,3], and moisture regulation as part of protective apparel [4]. For example, based on the 2010 U.S. Department of Energy (DOE) report, buildings consume $40 \%$ of the primary energy in the United States; space air-cooling accounts for about $12.7 \%$ of the total energy consumption and $13.0 \%$ of $\mathrm{CO}_{2}$ emission from buildings [5]. The current building space cooling by vapor compression system has two main disadvantages: Energy consumption is high and the process is accompanied by water condensation from fresh humid air intake. Therefore, it is highly desirable to develop a novel airconditioning system that can efficiently control building temperature and humidity in warm and humid climates. Several new dehumidification technologies have been reported over the last two decades, including electro-osmotic dehumidification [6], solid adsorbents [7], and liquid dessicants [8,9]. However, these technologies have high capital costs and exhibit no significant decrease in energy consumption and have therefore not yet been widely adopted for buildings.

In this line of research many different polymer membrane materials have been investigated for the removal of water vapor from gas streams [10,11,12]. Water vapor/air separation is driven by a pressure gradient of water vapor between two sides of the membrane under a constant temperature. Membrane dehumidification is a green process during which no environmentally harmful emission is generated. Semi-permeable membrane materials are used to selectively remove water vapor from a humid air stream. The water vapor permeability and the corresponding $\mathrm{H}_{2} \mathrm{O} / \mathrm{N}_{2}$ selectivity strongly depend on the materials used. Membrane materials like PEBAX ${ }^{\circledR}$ MV $1074^{1}$ and sulfonated poly(ether ether ketone) (SPEEK) exhibit good performances. Commercially available PEBAX ${ }^{\circledR}$ MV 1074 combines a high water vapor

\footnotetext{
${ }^{1}$ http://www.arkema.com/en/
} 
permeability of $1.6 \times 10^{5}$ Barrer with a medium $\mathrm{H}_{2} \mathrm{O} / \mathrm{N}_{2}$ selectivity $\left(2.0 \times 10^{5}\right)$. SPEEK offers a lower water vapor permeability of $7.0 \times 10^{4}$ Barrer combined with an extremely high $\mathrm{H}_{2} \mathrm{O} / \mathrm{N}_{2}$ selectivity $\left(1.0 \times 10^{7}\right)[3]$.

Graphene oxide (GO) sheets, which are oxidative exfoliation products of graphite, have attracted growing interest in areas of energy storage and separation technologies [13]. In particular, GO sheets, which contain carboxyl, hydroxyl, and epoxide functionalities in different ratios, offer great potential as material for functional composite membranes that have excellent water transport properties [14]. Unlike GO, if one uses pristine graphene monolayers, one has to create highly engineered pores in the sheets to allow permeation [15]. Despite increased academic interest in water transport through graphene and GO membranes significant technical difficulties still hinder the fabrication of such membranes for real-world water separation applications. For instance, it is still impractical to prepare large areas of monolayer graphene [13]. It is also extremely challenging to generate a high density of nanopores with controllable, relatively uniform pore sizes on graphene sheets [16].

Using stacked GO nanosheets instead of nanoporous graphene-based membranes, offers a more realistic approach to fabricating water vapor-selective membranes. The two dimensional (2D) channels between the stacked GO nanosheets allow water molecules to pass through while rejecting unwanted solutes, a mechanism similar to that of water transport through pores in traditional membrane structures. Molecular simulations have predicted that water has a very large slip length (i.e., low friction) on graphene surfaces, resulting in an extremely high rate of water flow in planar graphene nanochannels $[17,18]$. This property promises high water flux in stacked GO nanosheets as well. In addition, GO nanosheets can be mass-produced via chemical oxidization and ultrasonic exfoliation of graphite [19,20], thereby significantly lowering the 
material manufacturing cost and facilitating scale-up of the membrane synthesis process. Furthermore, the functional groups (particularly carboxyl groups) on GO nanosheets provide convenient sites for further functionalization to enhance properties such as specific interactions with water contaminants [21]. Therefore, GO becomes an ideal material for fabricating highperformance membranes for water vapor separation. It has been demonstrated that membranes consisting of stacked GO nanosheets, made by a simple solution filtration method, exhibit excellent mechanical strength in dry conditions and can be used as a gas/vapor separation membrane. Superfast permeation of water vapor through such a GO membrane was observed and credited to a nearly frictionless flow of monolayered water through the planar capillaries formed by the closely stacked GO nanosheets [13].

In this paper, we report dehumidification results from flowing gas mixtures through freestanding GO membrane samples prepared by a casting method. This first demonstration of a GO membrane for water vapor separation shows outstanding water vapor permeability and $\mathrm{H}_{2} \mathrm{O} / \mathrm{N}_{2}$ selectivity.

\section{Experimental}

$2.1 \mathrm{GO}$ synthesis and membrane preparation

Graphite flakes (Sigma-Aldrich, cat \#332461, $150 \mu$ m flakes) were oxidized using the method reported by Marcano et al. [19]. This “improved method” (with respect to Hummers' method [22]) uses increasing the amount of $\mathrm{KMnO}_{4}$ and a 9:1 mixture of $\mathrm{H}_{2} \mathrm{SO}_{4} / \mathrm{H}_{3} \mathrm{PO}_{4}$, excluding the $\mathrm{NaNO}_{3}$ to improve the efficiency of the oxidation process. Details of the synthesis procedure are described in the supporting information. Subsequently an aqueous GO slurry, containing about $0.89 \mathrm{wt} . \%$ of flakes, was poured onto a polished Teflon plate. The slurry was 
spread out with a glass bar. To achieve the desired film thickness, 5-10 layers of scotch tape (3M) were taped onto the Teflon plate acting as spacers. The sample was dried overnight, and then the film was lifted off using adhesive tape and careful peeling.

2.2 Membrane characterization (material)

X-ray diffraction (XRD) pattern of GO membranes were obtained on a Rigaku desktop X-ray diffractometer using $\mathrm{Cu} \mathrm{K \alpha}(1.54059 \AA)$ radiation with the X-ray generator operating at $20 \mathrm{kV}$ and $30 \mathrm{~mA}$. Data were collected for a $2 \theta$ range of 5.0-20.0 at an angular resolution of $0.01 \%$. The morphology of GO membranes was studied by scanning electron microscopy (SEM) using a JEOL microscope model JSM5900LV. Membrane samples for SEM analysis were put on carbon sticky tape and plasma coated with Pt/Au for 240 s. Fourier Transform Infrared (FTIR) spectra were recorded over a range from $400-4000 \mathrm{~cm}^{-1}$ with a resolution of $2.0 \mathrm{~cm}^{-1}$, using a Nexus 670 FTIR spectrometer (Thermo Nicolet). X-ray photoelectron spectroscopy (XPS) measurements were performed using a Quantera Scanning X-ray Microprobe (Physical Electronics). This system uses a focused monochromatic Al Ka x-rays (1486.7 eV) source and a spherical section analyzer. The instrument has a 32 channel detector. The X-ray beam used was a $100 \mathrm{~W}, 100 \mu \mathrm{m}$ diameter beam that was rastered over a $1.2 \mathrm{~mm}$ by $0.1 \mathrm{~mm}$ rectangle on the sample. The X-ray beam is incident normal to the sample and the photoelectron detector was at $45^{\circ}$ off-normal. High energy resolution spectra were collected using a pass-energy of $69.0 \mathrm{eV}$ with a step size of $0.125 \mathrm{eV}$. For the $\mathrm{Ag} 3 \mathrm{~d} 5 / 2$ line, these conditions produced a FWHM of 0.91 $\mathrm{eV}$. The binding energy (BE) scale is calibrated using the $\mathrm{Cu} 2 \mathrm{p} 3 / 2$ line at $932.62 \pm 0.05 \mathrm{eV}$ and Au $4 \mathrm{f} 7 / 2$ at $83.96 \pm 0.05 \mathrm{eV}$ for known high purity references. 


\subsection{Water vapor permeation test}

Membrane permeation tests were carried out using the method reported by Liu et. al. in 2011 (see supporting information for details about the procedure) [23].

The permeation flux, permeance, and selectivity were calculated from experimental measurements according to the following equations:

$$
\begin{gathered}
J_{m}=\frac{W_{p}}{\left(S A_{m}\right) t} \\
P_{i}=\frac{F_{i, p}}{\left(S A_{m}\right)(\Delta p i)} \\
S_{i j}=\frac{\left(y_{i} / y_{j}\right)_{p}}{\left(x_{i} / y_{j}\right)_{f}}
\end{gathered}
$$

With $J_{m}=$ permeation flux $\left[\mathrm{kg} / \mathrm{m}^{2} / \mathrm{h}\right], P_{i}=$ permeance of species $i\left[\mathrm{~mol} / \mathrm{m}^{2} / \mathrm{s} / \mathrm{Pa}\right], S_{i j}=$ separation factor of species $i$ to $j, W_{p}=$ amount of liquid condensed in the liquid $\mathrm{N}_{2}$ trap, $S A_{m}=$ working surface area of the membrane $\left[\mathrm{m}^{2}\right], t=$ testing duration time to collect $W_{p}[\mathrm{~s}], F_{i}=$ permeation flow rate of species $i[\mathrm{~mol} / \mathrm{s}], \Delta p_{i}=$ partial pressure differential of species $i$ between the feed and permeate sides [Pa], $y_{i}=$ molar fraction of species $i$ on the permeate side, $y_{j}=$ molar fraction of species $j$ on the permeate side, $x_{i}=$ molar fraction of species $i$ on the feed side, and $x_{j}=$ molar fraction of species $j$ on the feed side. 


\section{Results and Discussion}

\subsection{Membrane characteristics}

Materials characterization results of a typical GO membrane are summarized in Fig. 1. Fig. 1a shows a photograph of the free-standing, flexible GO membrane prepared by the described casting method. In the XRD pattern (Fig. 1b) the (001) peak of the GO membrane material is located at $2 \theta=11.18^{\circ}(d$-spacing: $7.91 \AA)$. None of the characteristic peaks of the graphite starting material (e.g. the $100 \%$ peak at $2 \theta=26.96^{\circ}$ (002) [24]; Fig. $1 \mathrm{~b}$ inset) could be detected, which indicates that pure, highly oxidized GO was synthesized. High resolution XPS scans of the carbon region (C1s) were performed on a GO membrane. Deconvolution of the spectrum's C1s region revealed the presence of a strong peak at $\sim 286.6 \mathrm{eV}$, corresponding to large amounts of $\mathrm{sp}^{3}$ carbon (C-O), with contributions of $\underline{\mathrm{C}}=\mathrm{C}(\sim 284.5 \mathrm{eV}), \underline{\mathrm{C}}=\mathrm{O}(\sim 287.8 \mathrm{eV})$ and carboxyl (O$\underline{\mathrm{C}}=\mathrm{O}$ )/lactone/ester ( $288.9 \mathrm{eV}$ ) groups (Fig.1c). The high content of oxygen in the membrane material is due to the strongly oxidative exfoliation during the synthesis procedure. Table 1 lists the quantified atom percentage of carbon and oxygen found in the surface composition of GO membranes as determined by XPS. As shown Fig. 1d, thus prepared GO membranes exhibit significant surface roughness, most likely formed during the drying process (water evaporation on the PTFE plate). GO flakes coated on Si(100) surface are ave. 20-40 $\mu \mathrm{m}$ in their lateral dimension and they consist of 1-2 GO layers (Fig. 2). 

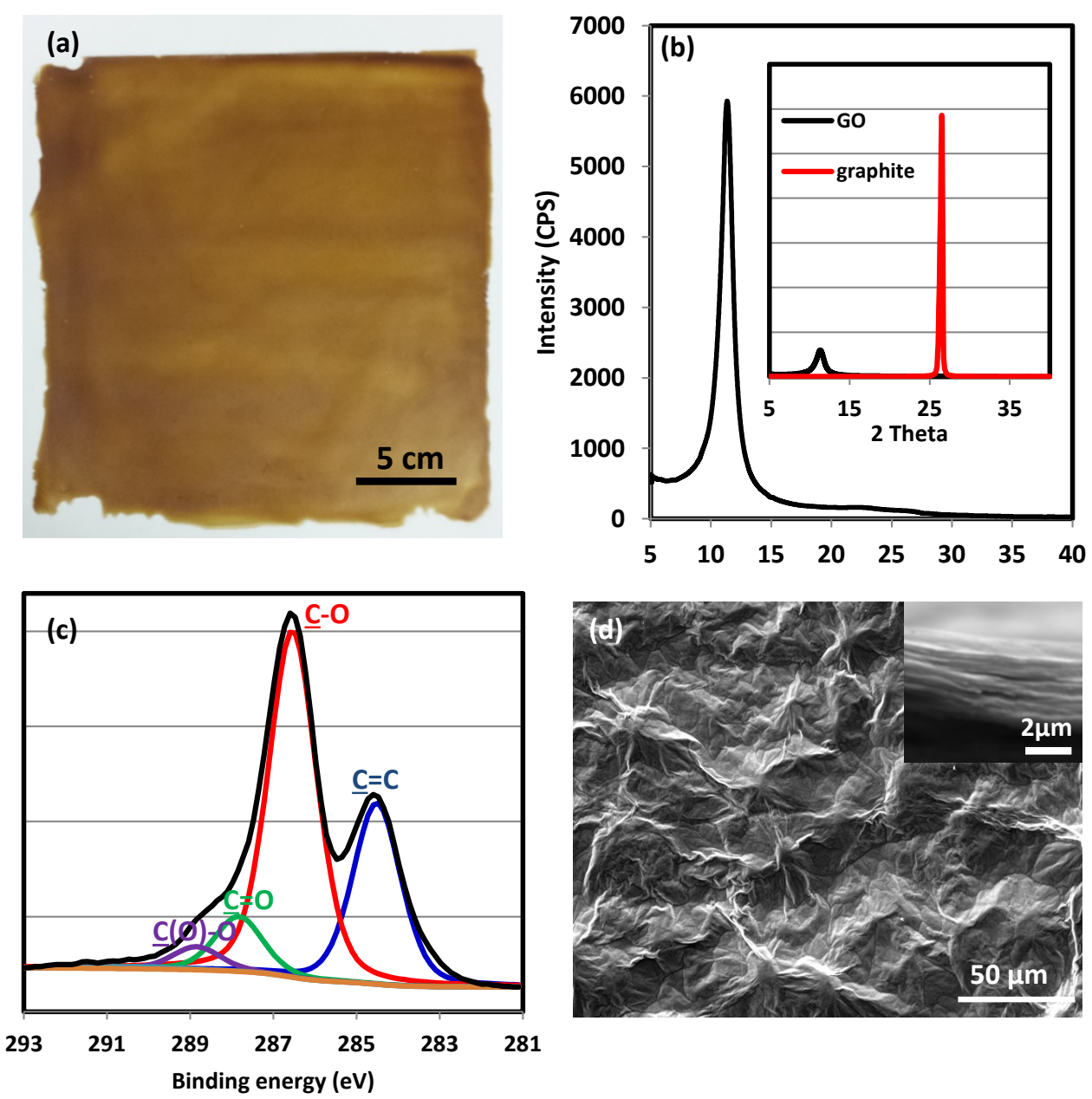

Fig. 1. (a) Photograph of a typical GO membrane prepared via a casting process, (b) region of the XRD pattern, which contains the diffraction peak indicating the $d$-spacing between GO layers, and inset shows the graphite starting material and GO, (c) XPS (C1s region), and (d) SEM image of the GO membrane surface.

Table 1.

Physical properties of a free-standing GO membrane prepared by the improved method.

\begin{tabular}{ccccccccc}
\hline$d$-spacing $(\AA)$ & Ave flake & C/O ratio & \multicolumn{3}{c}{ C1s (at.\%) } & & Thickness \\
& & & & & & \\
& size $(\mu \mathrm{m})$ & $($ at.\%) & $\underline{\mathrm{C}=\mathrm{C}}$ & $\underline{\mathrm{C}-\mathrm{O}}$ & $\underline{\mathrm{C}=\mathrm{O}}$ & $\underline{\mathrm{C}}(\mathrm{O})-\mathrm{O}$ & $(\mu \mathrm{m})$ \\
\hline 7.91 & $20-40$ & $54.6 / 45.4$ & 26.3 & 62.4 & 8.8 & 2.4 & 6.0
\end{tabular}



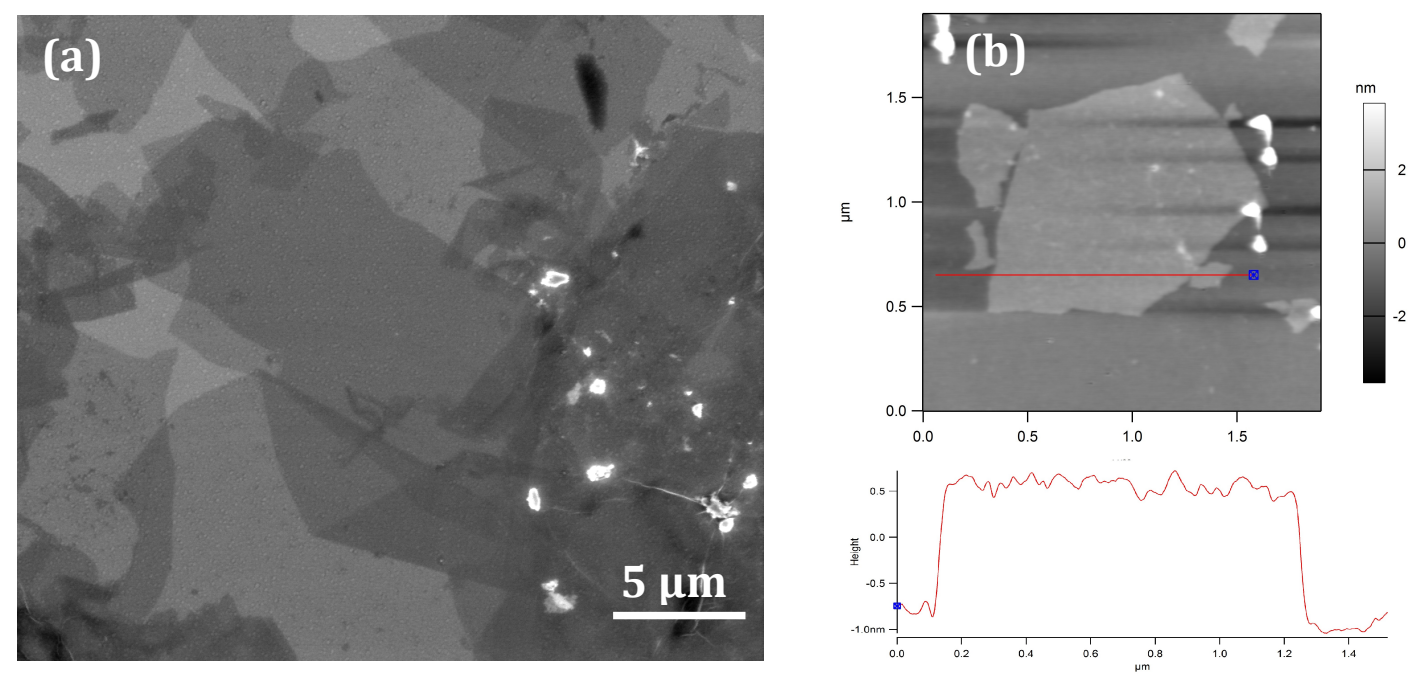

Fig. 2. (a) Scanning electron microscope (SEM) and (b) atomic force microscope images of GO flakes including a height profile of the GO flake.

Fig. 3 shows the FTIR spectrum of a GO membrane. The GO membrane shows a strong broad feature of overlapping vibration modes between $3600-2800 \mathrm{~cm}^{-1}$, which can be attributed to water clusters associated with $\mathrm{O}-\mathrm{H}$ groups on the membrane surface. Other identifiable vibration modes are $\mathrm{C}=\mathrm{O}\left(1732 \mathrm{~cm}^{-1}\right)$, aromatic $\mathrm{C}=\mathrm{C}\left(1611 \mathrm{~cm}^{-1}\right)$, carboxy $\mathrm{C}-\mathrm{O}\left(1410 \mathrm{~cm}^{-1}\right)$, epoxy C-O (1226 $\left.\mathrm{cm}^{-1}\right)$, and alkoxy C-O stretches $\left(1051 \mathrm{~cm}^{-1}\right)$ [25].

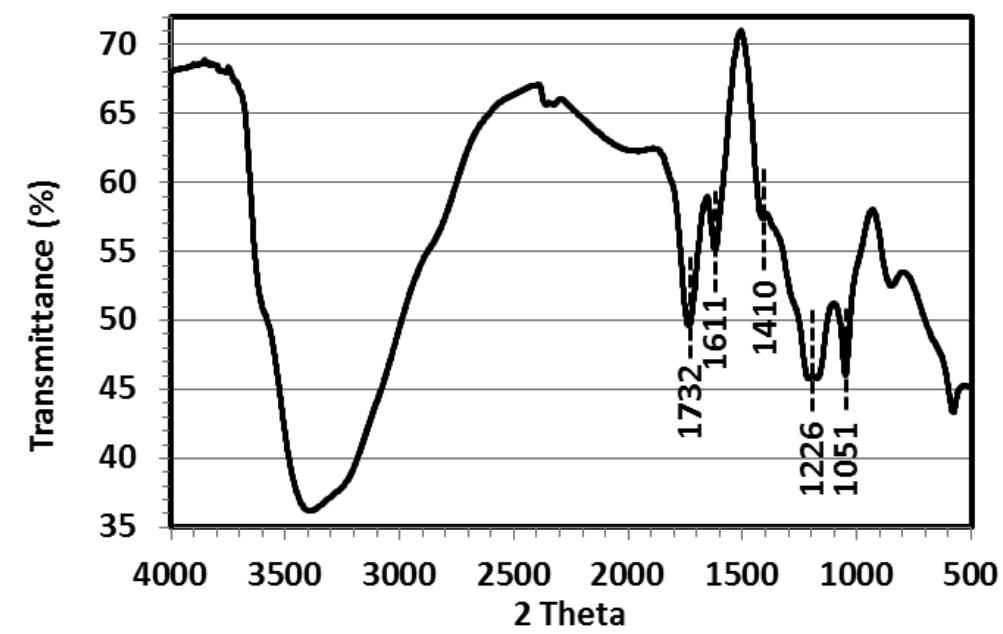

Fig. 3. FTIR spectrum of a GO membrane 


\subsection{Gas and water vapor permeation}

To investigate the potential of GO membranes for dehumidification, the single gas permeability for nitrogen and oxygen was measured. In addition, the mixed nitrogen and water vapor permeability of the same GO membrane was also assessed. The permeation results for a single gas $\left(\mathrm{N}_{2}, \mathrm{O}_{2}\right)$ and gas mixtures $\left(\mathrm{N}_{2}\right.$ plus $\left.\mathrm{H}_{2} \mathrm{O}\right)$ through $\mathrm{GO}$ membranes are summarized in Table 2. GO membranes show very low permeance for pure gases $\left(\mathrm{N}_{2}, \mathrm{O}_{2}\right)$ in the absence of water vapor. The oxygen permeability is slightly higher than that of nitrogen, and both permeabilities decrease as the cell temperature increases. This observation is surprisely different from the behavior of polymer membranes, where gas permeabilities are enhanced at higher operation temperatures due to the swelling of the polymer [3]. This might be due to decrease of the interlayer spacing of GO membranes as the temperature increases [14, 26].

\section{Table 2}

Gas permeation results for GO membranes at different mole fraction of water and different cell temperatures, respectively.

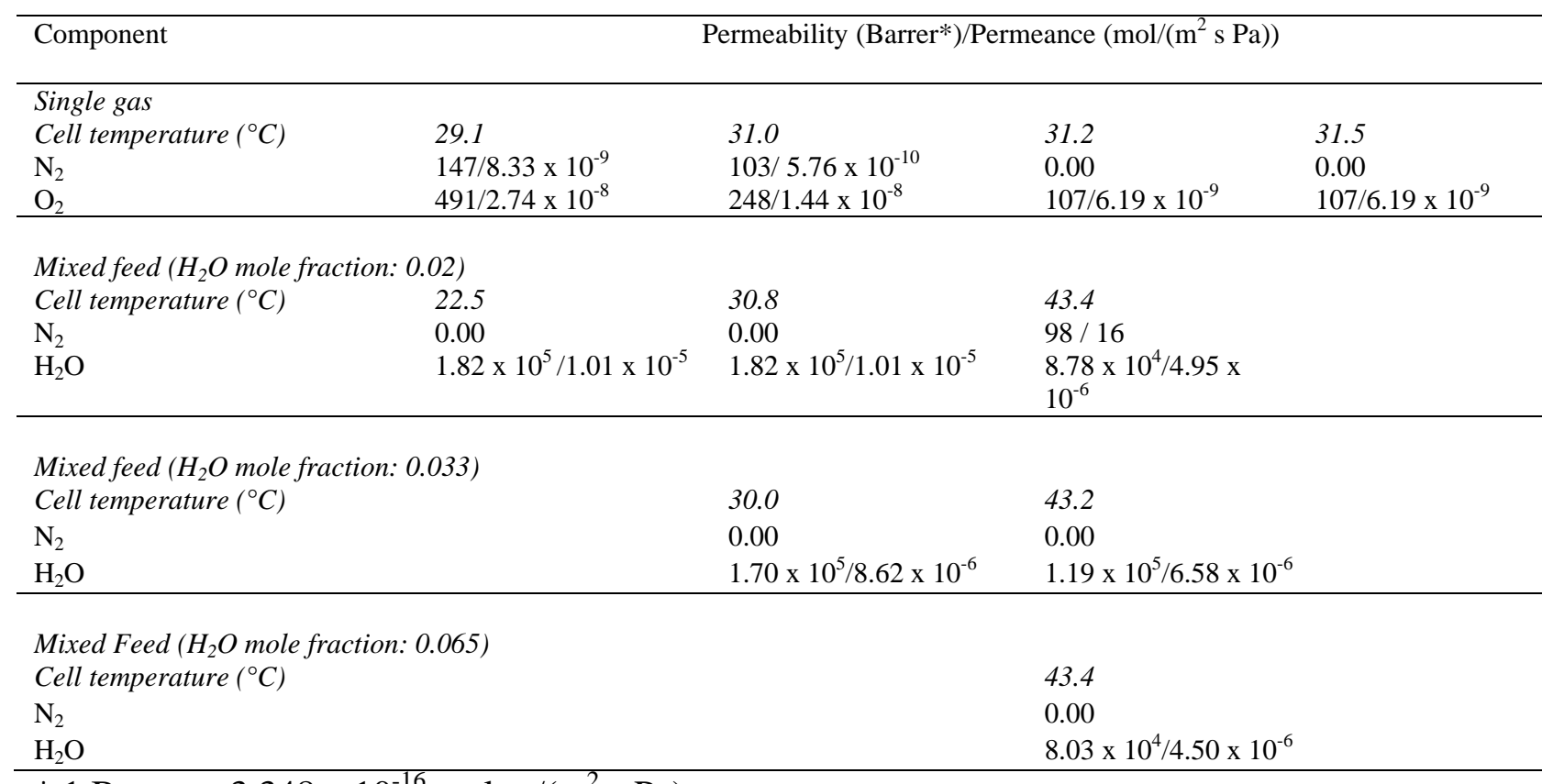

\footnotetext{
* 1 Barrer $=3.348 \times 10^{-16} \mathrm{~mol} \mathrm{~m} /\left(\mathrm{m}^{2} \mathrm{~s} \mathrm{~Pa}\right)$
} 
The permeation of water molecules across the membrane, however, is driven by a partial pressure gradient of water vapor in the $\mathrm{H}_{2} \mathrm{O} / \mathrm{N}_{2}$ gas feed, so that the water vapor flux becomes higher with increasing water content in the gas feed, i.e. higher mole fractions of water (humidity). Fig. 4a shows the water flux through GO membranes as a function of the test cell temperature for different mole fractions of water vapor: $0.014,0.02,0.033$ and 0.065 . As expected the water flux increases with increasing mole fractions of water, but more interestingly, the water flux seems to decrease with increasing cell temperature. as Nair et. al. suggested permeation may occur by slip-free flow of liquid like water between the layers [14]. Therefore, as cell temperature increases the amount of water decreases in the gallery spaces by the partitioning of water between liquid and vapor phase, this could reduce permeability. The influence of the test cell temperature on the water vapor permeance of GO membranes follows the same trend and is shown in Fig. S1 (see supporting information). It decreases with increasing test cell temperatures.
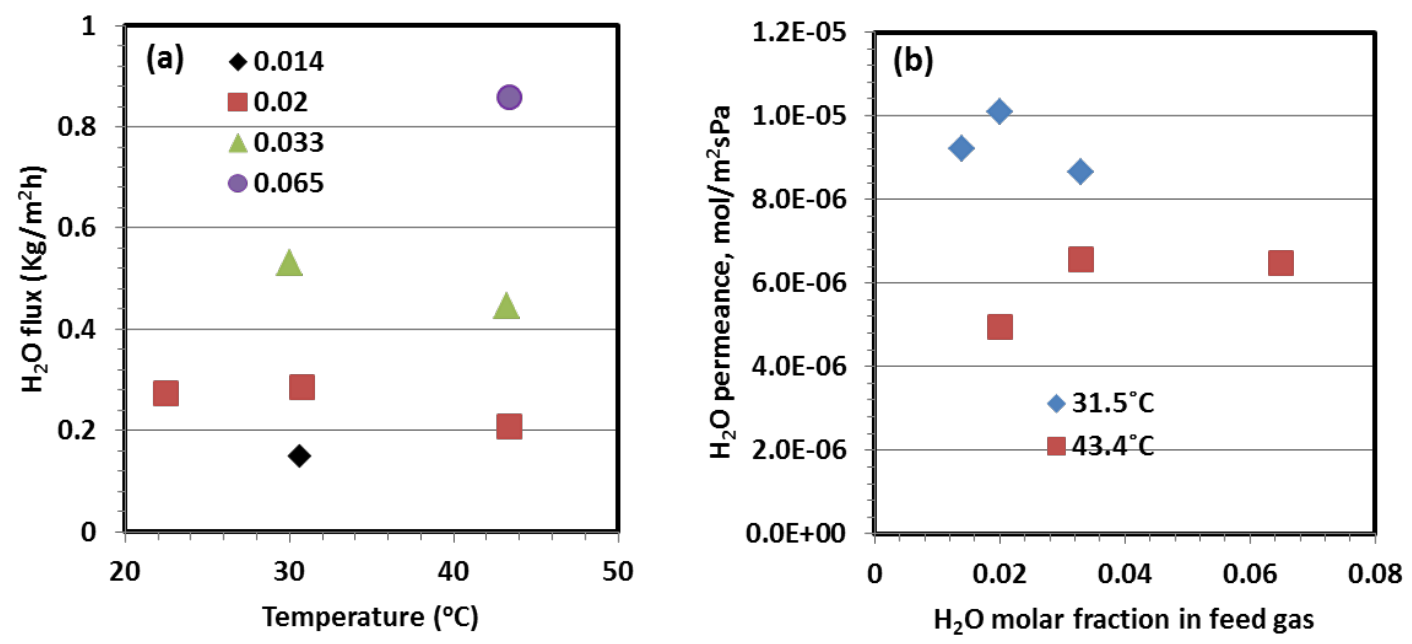
Fig. 4. Variation of (a) water flux through GO membranes as a function of the test cell temperature for different mole fractions of water vapor, and (b) water vapor permeance of GO membranes as a function of water mole fraction in feed gas at different operating cell temperature.

The presence of water vapor in the gas feed mixture significantly influences the gas permeability of GO membranes. Usually, gas permeabilities in polymer membranes are higher for the wet state of a membrane than for the dry state due to their swelling [3]. However, in the GO membranes $\mathrm{N}_{2}$ gas permeabilities remain below the detection limit of our system compared to the exceptional water vapor permeability (up to $1.82 \times 10^{5}$ Barrer), even as the water vapor permeability of the GO membranes decreases slightly with increasing cell temperatures. This indicates that GO materials are much more stable and less sensitive to temperature variations than polymer materials in the presence of water vapor at temperature $\leq 40{ }^{\circ} \mathrm{C}$. However, at temperatures higher than $40{ }^{\circ} \mathrm{C}$ the GO surface becomes less hydrophilic, which leads to decreased water vapor permeability and detectable $\mathrm{N}_{2}$ permeability at lower mole fractions of water (e.g. 0.02) [27]. Overall, our data indicates that the selectivity of water vapor to $\mathrm{N}_{2}$ gas is exceptionally high for GO membranes, which are basically impermeable to $\mathrm{N}_{2}$ gas. The water vapor permeability and selectivity over $\mathrm{N}_{2}$ gas are comparable to commercially available polymer membranes, such as $\mathrm{PEBAX}{ }^{\circledR} \mathrm{MV} 1074$ (water vapor permeability $=1.6 \times 10^{5}$ Barrer, selectivity $\left.=2.0 \times 10^{5}\right)[12]$.

Fig. 4b shows the water vapor permeance of GO membranes as a function of humidity, i.e. mole fraction of water vapor in the feed gas, at different test cell temperature in a $\mathrm{N}_{2} / \mathrm{H}_{2} \mathrm{O}$ gas feed mixture. In all cases the $\mathrm{N}_{2}$ permeance is close to lower detection limit of the instrument at the same time (Table 2). The water vapor permeance is higher at lower test cell temperatures, and remains rather steady for different mole fractions of water, i.e. different humidities. As 
mentioned above, this leads to very large $\mathrm{H}_{2} \mathrm{O} / \mathrm{N}_{2}$ selectivities for $\mathrm{GO}$ membranes under the various test conditions, with the exception of one condition we explored: at a low humidity (0.02 mole fraction of water) and high temperature $\left(43.4^{\circ} \mathrm{C}\right)$ the $\mathrm{H}_{2} \mathrm{O} / \mathrm{N}_{2}$ selectivity was found to decrease to $\sim 816$ (down from infinity at higher humidity or at lower temperature, Table 2). As discussed earlier, this might be resulted from the decreased amount of water in the interlayer spacing at the temperature, and this could dramatically decrease permeability [14]. However, even under this condition GO membranes still exhibit excellent barrier behavior with respect to nitrogen. Unfortunately, the humidity and temperature ranges on the water vapor permeance of GO membranes are limited. Excessive water vapor adsorption at higher test cell temperatures and/or humidities leads to mechanical failure of the GO membrane and leakage is observed.

In the water vapor permeation test cell GO membranes were continuously measured for 4 days under humid conditions. After removal from the test cell no structural degradation of the GO membranes were observable, but both membrane surfaces were covered with substantial amounts of condensed water vapor. One of the GO membranes was investigated by XRD right after the water vapor permeation test and then again after drying it in air for $30 \mathrm{~d}$ (XRD recorded on the side of the membrane facing the feed gas stream, Fig. 5). The XRD pattern of the wet GO membrane after testing showed a large expansion of the $d$-spacing (11.40 $\AA$ ) compared to the $d$ spacing of an as-prepared membrane (7.91 $\AA$ ). The intensity of the peak was dramatically decreased and exhibited a slightly deformed pattern. However, after drying for $30 \mathrm{~d}$ in air $d$ spacing decreased again to $7.62 \AA$, almost recovering to its original value. 


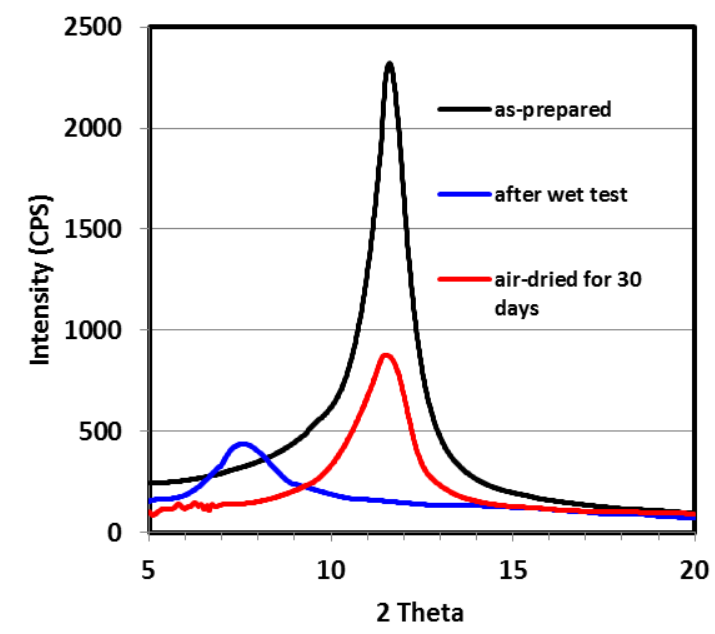

Fig. 5. XRD pattern of an as-prepared GO membrane (black), a GO membrane right after a water vapor permeation test (blue), and the same membrane after being dried in air for $30 \mathrm{~d}$ (red).

\subsection{Comparison of GO membrane water separation performance}

Water vapor permeabilities and selectivities of $\mathrm{H}_{2} \mathrm{O} / \mathrm{N}_{2}$ of several membrane materials that are being used or investigated for dehumidification applications are listed in Table 2 and compared with the properties of our GO membranes. For convenience membrane permeability and permeance are listed separately in Barrer and $\mathrm{mol} /\left(\mathrm{m}^{2} \mathrm{sPa}\right)$, respectively. At low humidity (0.02 mole fraction $\left.\mathrm{H}_{2} \mathrm{O}\right)$ and temperature $\left(\leq 40{ }^{\circ} \mathrm{C}\right)$ the $\mathrm{GO}$ membranes prepared in this work exhibit outstanding water vapor permeability of $1.82 \times 10^{5}$ Barrer and permeance of $1.01 \times 10^{-5}$ $\mathrm{mol} /\left(\mathrm{m}^{2} \mathrm{~s} \mathrm{~Pa}\right)$, which is superior to most values documented in Table 2, including those for all polymer membranes. It is similar to the permeability reported for [emim] $\left[\mathrm{Tf}_{2} \mathrm{~N}\right]$, an ionic liquid. For a NaA zeolite/Ni sheet membrane a significantly higher water vapor permeability of $6.09 \mathrm{x}$ $10^{4}$ Barrer has been reported, but this membrane exhibits a low selectivity for $\mathrm{H}_{2} \mathrm{O} / \mathrm{N}_{2}$ gas mixtures (178). Regarding the $\mathrm{H}_{2} \mathrm{O} / \mathrm{N}_{2}$ selectivity, values as high as $1.0 \times 10^{7}$ were reported for SPEEK and PEBAX ${ }^{\circledR}$ MV 1074 polymers. Other membranes, including polyethylene glycol and [emim] $\left[\mathrm{Tf}_{2} \mathrm{~N}\right]$, showed $\mathrm{H}_{2} \mathrm{O} / \mathrm{N}_{2}$ selectivities above 2000. Unfortunately, those selectivity 
numbers were mostly measured using single gas experiments and therefore do not represent actual separation factors of a gas mixture. On the other hand, our GO membranes exhibit excellent $\mathrm{H}_{2} \mathrm{O} / \mathrm{N}_{2}$ selectivity $>10^{4}$ in a $\mathrm{H}_{2} \mathrm{O} / \mathrm{N}_{2}$ gas mixture. This number is clearly better than those of other membranes in gas mixtures.

\section{Table 2}

Membrane materials used for air defumidification.

\begin{tabular}{lllll}
\hline Membrane material & $\begin{array}{l}\text { Water vapor } \\
\text { permeability, Barrer }\end{array}$ & $\begin{array}{l}\text { Water vapor permeance, } \\
\mathrm{mol} /\left(\mathrm{m}^{2} \mathrm{~s} \mathrm{~Pa}\right)\end{array}$ & $\mathrm{H}_{2} \mathrm{O} / \mathrm{N}_{2}$ selectivity & Reference \\
\hline $\begin{array}{l}\text { Sulfonated poly(ether } \\
\text { ether ketone) (SPEEK) }\end{array}$ & $7.00 \times 10^{4}$ & $4.60 \times 10^{-7}$ & $1.0 \times 10^{7 *}$ & {$[3,28]$} \\
$\begin{array}{l}\text { PEBAX } \\
\text { MV 1074 }\end{array}$ & $1.60 \times 10^{5}$ & $2.87 \times 10^{-6}$ & $2.0 \times 10^{5 *}$ & {$[3]$} \\
$\begin{array}{l}\text { Ionic liquid } \\
\text { [emim][Tf2N] }\end{array}$ & $2.83 \times 10^{5}$ & $2.10 \times 10^{-7}$ & $3843^{*}$ & {$[28]$} \\
$\begin{array}{l}\text { Stabilized liquid poly } \\
\text { ethylene glycol }\end{array}$ & $1.50 \times 10^{4}$ & $7.50 \times 10^{-7}$ & $2000^{*}$ & {$[29]$} \\
NaA zeolite/Ni sheet & $6.09 \times 10^{4}$ & $6.8 \times 10^{-6}$ & 178 & {$[30]$} \\
& $1.82 \times 10^{5}$ & $1.01 \times 10^{-5}$ & $>10^{4}$ & this work \\
\hline
\end{tabular}

*The selectivity was calculated as a ratio of relative permeability of single gas.

This comparison against other materials for dehumidification membranes is encouraging. However, currently there are a couple of limitations to the use of GO membranes for dehumidification. First, as previously mentioned, GO membranes showed decreased water vapor/ $\mathrm{N}_{2}$ selectivity as the separation temperature increased. Second, GO membranes can be recycled, but currently it is a slow process to do so. Third, GO membranes used in this study are too fragile to be used in any system with cross-membrane pressures $>2$ bar, which makes this generation of GO membranes not suitable for the treatment of natural gases, where operating pressure differentials could be greater than 12 bar [31]. On the other hand, GO membranes could 
be competitive for lower pressure gas separation systems such as flue gas dehydration and building ventilation systems [3].

\section{Conclusions}

We have demonstrated that GO membranes with excellent water vapor permeability and $\mathrm{H}_{2} \mathrm{O} / \mathrm{N}_{2}$ selectivity can be synthesized via a simple casting approach. The GO membranes exhibit a number of fascinating advantages over existing membranes: first, graphite is an inexpensive raw material, which significantly lowers the membrane fabrication cost; second, the synthesis procedures for both GO nanosheets and GO membranes are simple and scalable; third, water vapor permeability through GO membranes dominates the permeability of other gases such as $\mathrm{O}_{2}$ and $\mathrm{N}_{2}$, leading to exceptional selectivities. Further adjusting the properties of the GO starting material, such as flake size, surface functionalization or incorporating a support material to increase mechanical stability, is expected to yield enhanced performances with regard to water vapor flux and salt rejection.

\section{Acknowledgement}

The research described in this paper is part of the Materials Synthesis, Simulation, and across the Scale $\left(\mathrm{MS}^{3}\right.$ ) Initiative at Pacific Northwest National Laboratory (PNNL). It was conducted under the Laboratory Directed Research and Development Program at PNNL, a multi-program national laboratory operated by Battelle for the U.S. Department of Energy. A portion of the research was performed using EMSL (http://www.emsl.pnl.gov; user proposal \#48749), a national scientific user facility sponsored by the DOE's Office of Biological and Environmental Research (BER) and located at PNNL. 


\section{References}

[1] L. Harriman III, J. Judge, Dehumidification equipment advances, ASHRAE J. 44 (2002) 22-29.

[2] R. W. Baker, Future directions of membrane gas separation technology, Ind. Eng. Chem. Res. 41 (2002) 1393-1411.

[3] H. Sijbesma, K. Nymeijer, R. van Marwijk, R. Heijboer, J. Potreck, M. Wessling, Flue gas dehydration using polymer membranes, J. Membr. Sci. 313 (2008) 263-276.

[4] B. Gebben, A water vapor-peameable membrane from block copolymers of poly(butyl terephthalate) and polyethylene oxide, J. Membr. Sci. 113 (1996) 323-329.

[5] US DOE Report DE-FOA-0000239, Building Energy Efficiency Through Innovative Thermodevices, 2010.

[6] B. Li, Q.Y. Lin, Y.Y. Yan, Development of solid desiccant dehumidification using electro-osmosis regeneration method for HVAC application, Build. Environ. 48 (2012) 128-134.

[7] M.Ö. Kanoğlu, M. Çarpınlığlu, M. Yıldırım, Energy and energy analyses of an experimental open-cycle desiccant cooling system, Appl. Therm. Engineer. 24 (2004) 919-932.

[8] Y. Yin, X. Zhang, Z. Chen, Experimental study on dehumidifier and regenerator of liquid desiccant cooling air conditioning system, Build. Environ. 42 (2007) 2505-2511.

[9] W. Kessling, E. Laevemann, M. Peltzer, Energy storage in open cycle liquid desiccant cooling systems, Inter. J. Refriger. 21 (1998) 150-156.

[10] K. Kneifel, S. Nowak, W. Albrecht, R. Hilke, R. Rust, K.-V. Peinemann, Hollow fiber membrane contactor for air humidity control: modules and membranes, J. Membr. Sci. 276 (2006) 241-251.

[11] J. A. Barrie, in: J. Crank, G. S. Park (Eds.), Diffusion in polymers, Academic Press, New York, 1968.

[12] S. J. Metz, W.J.C. van de Ven, M.H.V. Mulder, M. Wessling, Mixed gas water vapor/ $\mathrm{N}_{2}$ transport in poly(ethylene oxide) poly(butylene terephthalate) block copolymers, J. Membr. Sci. 266 (2005) 51-61.

[13] D. R. Dreyer, S. Park, C. W. Bielawski, R. S. Ruoff, The chemistry of graphene oxide, Chem. Soc. Rev. 39 (2010) 228- 240.

[14] R. R. Nair, H. A. Wu, P. N. Jayaram, I. V. Grigorieva, A. K. Geim, Unimpeded permeation of water through helium-leak-tight graphene-based membrane, Science 335 (2012) 442- 444. 
[15] D. Cohen-Tanugi, J. C. Grossman, Water desalination across nanoporous graphene, Nano Lett. 12 (2012) 3602- 3608.

[16] S. P. Koenig, L. D. Wang, J. Pellegrino, J. S. Bunch, Selective molecular sieving through porous graphene, Nat. Nanotechnol. 7 (2012) 728- 732.

[17] S. K. Kannam, B. D. Todd, J. S. Hansen, P. J. Davis, Interfacial slip friction at a fluidsolid cylindrical boundary, J. Chem. Phys. 136 (2012) 244704.

[18] G. Cicero, J. C. Grossman, E. Schwegler, F. Gygi, G. Galli, Water confined in nanotubes and between graphene sheets: A first principle study, J. Am. Chem. Soc. 120 (2008) 18711878 .

[19] D. C. Marcano, D. V. Kosynkin, J. M. Berlin, A. Sinitskii, Z. Z. Sun, A. Slesarev, et al., Improved synthesis of graphene oxide, ACS Nano 4 (2010) 4806- 4814.

[20] R. Cruz-Silva, A. Morelos-Gomez, H. Kim, H. Jang, F. Tristan, S. Vega-Diaz, et al., Super-stretchable graphene oxide macroscopic fibers with outstanding knotability fabricated by dry film scrolling, ACS Nano 8 (2014) 5959-5967.

[21] M. J. Fernandez-Merino, J. I. Paredes, S. Villar-Rodil, L. Guardia, P. Solis-Fernandez, D. Salinas-Torres, et al., Investigating the influence of surfactants on the stabilization of aqueous reduced graphene oxide dispersions and the characteristics of their composite films, Carbon 50 (2012) 3184- 3194.

[22] W. S. Hummers Jr., R. E. Offeman, Preparation of graphitic oxide. J. Am. Chem. Soc. 80 (1958) 1339-1339.

[23] W. Liu, J. Zhang, N. Canfield, L. Saraf, Preparation of robust, thin zeolite membrane sheet for molecular separation, Ind. Engineer. Chem. Res. 50 (2011) 11677-11689.

[24] JCPDS file \# 04-014-0347

[25] S. Park, D. A. Dikin, S. T. Nguyen, R. S. Ruoff, Graphene oxide sheets chemically crosslinked by polyallylamine, J. Phys. Chem. C 113 (2009) 15801-15804.

[26] A. Lerf, A. Buchsteiner, J. Pieper, S. Schöttl, I. Dekany, T. Szabo, H.P. Boehm, Hydration behavior and dynamics of water molecules in graphite oxide, J. Phys. Chem. Solids 67 (2006), 1106-1110.

[27] P. Scovazzo, Testing and evaluation of room temperature ionic liquid (RTIL) membranes for gas dehumidification, J. Membr. Sci. 355 (2010) 7-17.

[28] L. Jia, X. Xu, H. Zhang, J. Xu, Sulfonation of polyetheretherketone and its effect on permeation behavior to nitrogen and water vapor, J. Appl. Polym. Sci. 60 (1996) 1231-1237. 
[29] A. Ito, Dehumidification of air by a hygroscopic liquid membrane supported on surface of a hydrophobic microporous membrane, J. Membr. Sci. 175 (2000) 35-42.

[30] R. Xing, Y. Rao, W. TeGrotenhuis, N. Canfield, F. Zheng, D. W. Winiarski, W. Liu, Advanced thin zeolite/metal flat sheet membrane for energy efficient air dehumidification and conditioning, Chem. Engineer. Sci. 104 (2013) 596-609.

[31] W. J. Koros, R. Mahajan, Pushing the limits on possibilities for large scale gas separation: which strategies? J. Membr. Sci. 175 (2000) 181-196. 